THE UNIVERSITY OF MINNESOTA

GRADUATE SCHOOL

Report

of

Committee on Examination

This is to certify that we the undersigned, as a committee of the Graduate School, have given Harold Sheely Diehl final oral examination for the degree of Master of Arts . We recommend that the degree of Master of Arts be conferred upon the candidate.
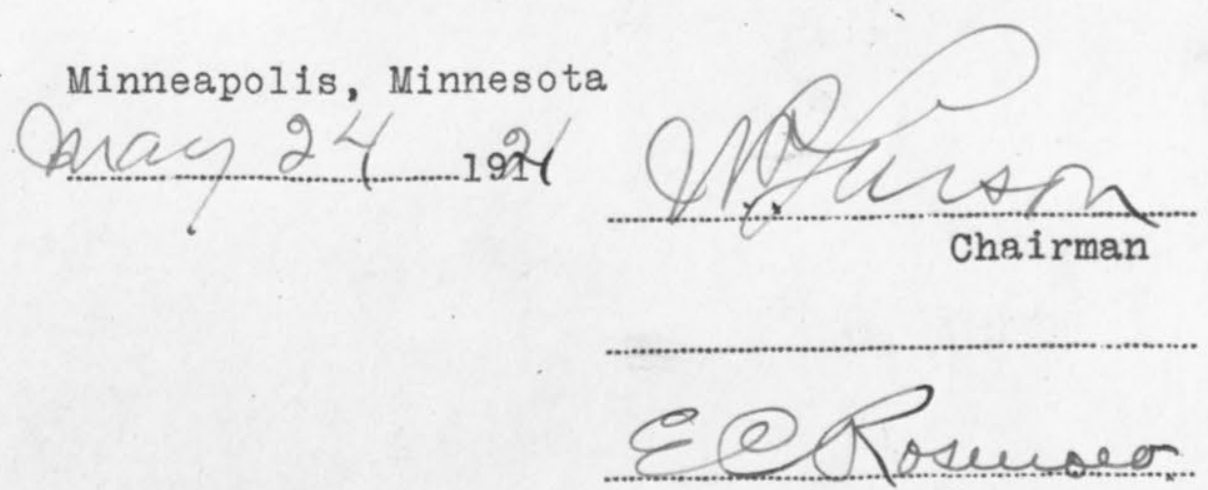

I., $20 l_{1}$

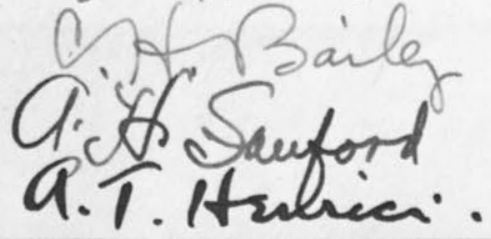




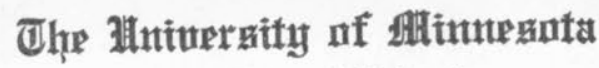

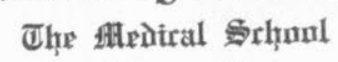

ettintrapritis

DEPARTMENT OF

BACTERIOLOGY AND IMMUNOLOGY

May 24, 1921.

Dean Guy Stanton Ford,

Graduate school.

Dear Dean Ford:-

I enclose herewith the report of

the Examining Committee of Earold s. Diehl.

I wish to call your attention to the fact that

the Thesis Committee passed on the thesis in

1918, before Mr. Diehl's Master's Thesis was

published. I believe the report of this

Comittee is on file in your office.

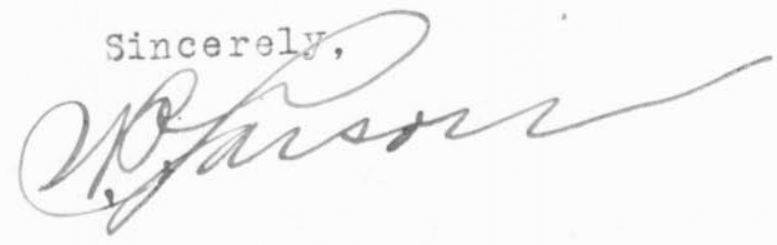

T. P. Iarson.

WPI: $\mathrm{K}$ 
THE MAYO FOUNDATION

FOR MEDICAL EDUCATION AND RESEARCH

ROCHESTER, MIN NESOTA, U.S.A.

February 19, 1919.

Dean G. S. Ford,

University of Minnesota,

Minneapolis, Minn.

IHy dear Dean Ford:

Herewith is the copy of the thesis submitted by Harold S. Diehl. Dr. Rosenow and Dr. Sanford agree that it is a very creditable contribution.

sincerely yours, W.F. Braash

IF. 

$\mathrm{Fermi}^{1}{ }^{1}$ in discussing this question, quotes the views of Fischer and Abderhalden. Their opinions are very similar and well worth repeating here. Emil Fischer states: "That most of our common ferments are mixed is very probable. But how far one should go in the differentiation of them is hard to say without experiment; and I must admit that most experiments which have been carried out in this connection possess but very little conclusive force. In any case, I believe that it is an exaggeration to assume for each protein that is attacked by pepsin and trypsin a special enzyme; for the necessary conclusion would be that one must assume for each glucosid a special enzyme, namely, for beta-methyl-glucosid and for beta-phenyl-glucosid. According to chemical analogies, I must hold this as being very improbable." Abderhalden expresses very much the same view when he says: "It is quite probable that pepsin and trypsin are not units, still, any sure proof of a gelatinase, casease, etc., is lacking in my conviction at the present time. So long as one is forced to work with unknown substrata and unknown ferments, sure conclusions are very hard to get."

In investigating this problem numerous proteins have been used to test enzyme action but gelatin has been more popular than any other. This is so chiefly because gelatin is easily prepared and any proteolytic action on it is discernible by direct observation. For this reason the digestion of gelatin has come to be looked on by many bacteriologists as an index of the proteolytic activity of bacteria, and in most cases it is quite satisfactory. Next to gelatin, casein probably has been most used, with variations of technic to determine the amount of its digestion. Hemoglobin, fibrin and other proteins have been tried with more or less satisfactory results.

\section{Review OF THE Literature.}

Pollak, ${ }^{2}$ after much experimenting, was convinced, (1) that the gelatinases are not identical with trypsin and (2) that a specific gelatinase exists. He bases this latter conclusion on the fact that in immune serum he could demonstrate an antigelatinase, which would suspend the gelatinolytic activity of solutions but would leave uninfluenced the serolytic. Hattori ${ }^{3}$ also claims to have demonstrated a specific gelatinase by the use of chemicals which would destroy the albumino-,, sero- and fibrino-lytic powers of a solution but would leave unimpaired the gelatinolytic power.

On the other hand, Duclaux ${ }^{4}$ thinks that the gelatinases and caseases are identical, and also assumes the identity of both of these with trypsin. And

1 Centralbl. f. Bakteriol., 1, O., 1913, 68, p. 433.

2 Cited by Marras (Hofmeister's Beitr., 1905), 6, p. 95.

, Cited by Marras, Arch. internationale de pharmacol., 1908, 18, p. 255.

1

- Microbiologie, 2, p. 618. 
fter extensive work with ferments obtained from animals and plants, incing bacteria, concludes that the proteolytic enzymes are identical with He found that, when fibrinases and caseases were present, gelatinprent; when that some gelatinases ases ivere also present; but that some bacteria which produce gelatinases do not produce fibrino- and caseino-lytic enzymes. From these findings he craws the conclusion that the same enzyme acts on all proteins, but that different proteins show various degrees of resistance.

De Waele and Vandevelde ${ }^{\circ}$ also believe that the differences in bacterial proteolysis are differences of intensity only. They state that on the different nitrogenous mediums all bacteria act quite similarly and that all feranism which liquefy gelatin also vigorously attack casein. To them this parallelism indicates that the liquefaction of gelatin and the solution of casein are due to one and the same ferment. However, they also find that bacteria produce various amounts of proteolytic ferments and that these ferments differ somewhat in their action; but that these differences depend not much on the bacteria as on the conditions and environment under which the enzymes are produced.

By the use of blood agar Eijkmann ${ }^{\tau}$ demonstrated an enzyme liberated by B. diphtheriae which was hemolytic but not proteolytic; and one liberated by a coccus from the air which digested gelatin but did not affect hemoglobin. To account for these differences he suggests several possibilities: (1) That different kinds of proteolytic enzymes exist, one of which will most readily act on gelatin and (2) that some metabolic products of the bacteria other than the ferments are responsible for some of the actions. The latter possibility is one which has not been mentioned by any other workers and is decidedly the less probable of the two. He also utilized agarelastin plates and on these observed the action of an enzyme that seemed to him identical with "the peptonizing ferment which liquefies gelatin." But, he states that there was always some incongruity in the clearing of the elastin and the liquefaction of the gelatin. This is exactly what one should expect, since gelatin and elastin though very closely related chemically are nevertheless not identical.

Mavrojannis," working with 8 types of bacteria, found that 5 of these digested gelatin to the stage of gelatoses; while the other 3 would carry them through to gelato-peptones. The gelatoses can be resolidified by mean: of formol while the gelato-peptones are unaffected by it. From these results 作 breaking down of gelatin, and that each of these was specific. These results, however, were soon refuted by Bogoluboff and Tiraboschi, ${ }^{10}$ but the work remains of some value because it helped to stimulate other investigations re latter authors found that the production of gelatoses 列 temperature, the reaction of the medium, and the length of time which the ferments are allowed to act.

Centralbl. f. Bakteriol., 1913, 1, O., 68, p. 433; 1913, 69, D. 465 .

Centralbl. f. Bakteriol., 1. O., 1905, 39, p. 353 .

Centralbl. f. Bakteriol., I, 1901, 1, p. 841.

s Compt rend Soc, de biol., 1903, 55, p. 1605.

- Bull. de l'Instit. Pasteur, 1907, 5, p. 429.

- Bull. de l'Instit. Pasteur, 1905, 3, p. 922 
The review of the literature shows a great diversity of results and conclusions, but gives the general impression that proteolytic enzymes are probably not specific. Still such a conception leaves unexplained some of the phenomena which these enzymes often exhibit. The statement is frequently encountered that the conditions and environment greatly influence the formation and properties of bacterial enzymes. Of all the factors that are included under the conditions and environment of enzyme formation, the composition of the medium is probably the most important.

In this connection the question suggests itself as to whether enzymes are preformed in the bacterial cell or whether they are produced by the organism only when the need for them arises. From our knowledge of vital processes in general it seems more probable that the bacterial cell should be endowed with the ability to elaborate ferments than that it should be a storehouse for the many ferments of which it has need at one time or another; or even that it should form all the ferments within its power each time that there is need for any one of them. The work of Jones ${ }^{11}$ substantiates this view by showing that B. proteus will not form gelatinases on gelatin when any glucose is present; but that as soon as the glucose has been used up the gelatinases appear. This would indicate that the ferments are not preformed in the bacterial cell, but that they are elaborated in response to need. Such a concept would further suggest that the many different kinds of nitrogenous mediums would probably stimulate the production of more than one type of enzyme. For example, it does not seem probable that an amino-acid and a highly complex protein would call forth the production of identical ferments. The present investigation was undertaken to determine, if possible, the extent of the influence of mediums on ferment production.

\section{TECHNIC}

The cultures to be studied for proteolytic enzymes were incubated at $37 \mathrm{C}$. for a period of 8 days. At the end of this time they were filtered through a sterile Berkefeld filter and $0.5 \mathrm{cc}$ of the filtrate was added to sterile gelatin and sterile casein solution. Control tubes were made in each case for comparison; and tests as to the sterility always made, all filtrates showing contamination being discarded.

The gelatin mediums used to test for proteolysis contained meat-infusion broth and $15 \%$ of gelatin. To several tubes of this in the hardened form was added a portion of each filtrate and the tubes were placed in an incubator at $20 \mathrm{C}$. Several other tubes of gelatin were liquefied before the

11 Jour. Infect. Dis., 1916, 19, p. 33. 
filtratc was added and then placed in an incubator at $37 \mathrm{C}$. Liquefaction in the latter case was determined by placing the tubes in ice water until the controls hardened. The results obtained by both methods coincided in every case, although the action was more rapid at the higher temperature.

The casein solution was made up according to the method of Füld and Gross. ${ }^{12}$ Ten gm. of Merck casein were dissolved in $100 \mathrm{c} \mathrm{c}$ of $10 \% \mathrm{Na}_{2} \mathrm{CO}_{3}$ solution, enough $10 \% \mathrm{HCl}$ added to just neutralize it and the volume made up to $500 \mathrm{cc}$ with physiologic salt solution. The whole was then filtered, and diluted with physiologic salt solution until the medium showed a definite clouding on the addition of acetic acid, but no heavy precpitate. This was placed in small test tubes, $5 \mathrm{c} \mathrm{c}$ to a tube, and sterilized. To test for enzymes $0.5 \mathrm{c} \mathrm{c}$ of the filtrate under examination was added to each of several tubes and incubated for 24 hours, after which undigested casein was determined by the addition of $0.2 \mathrm{c} \mathrm{c}$ of a solution of 45 parts of $90 \%$ alcohol, 5 parts of glacial acetic acid, and 50 parts of distilled water. The absence of any precipitate indicated that all the casein had been digested. With each tube of casein a control was run for comparison.

Various methods have been utilized for the detection of gelatinases in bacterial cultures. Of these, probably the most widely used is the carbolgelatin method in which $0.5 \mathrm{cc}$ of the culture to be tested is added to a tube of gelatin containing $5 \%$ carbolic acid. This is supposed to prevent the growth of the bacteria but to have no influence on the action of the enzymes. Eijkmann ${ }^{13}$ separates the enzymes from the bacteria by dialysis through agar, but the method seems impracticable when carrying out a large number of tests. Another method widely used is the one which gave the best results in our hands, namely, the separation of the enzymes from the bacteria by the filtration of the culture through a sterile Berkefeld filter. The method is laborious but, when properly carried out, very satisfactory.

Concerning the time at which the proteolytic activity of a culture is at its maximum, different views can be found. Von Gröer ${ }^{14}$ states that the most gelatinases of B. prodigiosus are found in a culture 3 weeks old. Malfitano and Strada ${ }^{15}$ found that on agar slants the proteases increase up to 24 hours and then decline. Mesernitsky ${ }^{16}$ agrees with the work of Von Gröer on B. prodigiosus in finding that the gelatinases appear at the beginning of the 6 th day and increase up to the 21 st day. Bertiau ${ }^{17}$ working with B. pyocyaneus and B. subtilis concluded that notable ferments exist in broth cultures at the end of 2 days and increase up to the 8 th day, after which they decrease slowly. In our work all cultures were tested at the end of 8 days and, in case of negative results, were tèsted again after a greater length of time, but never did positive results appear in cultures which were negative at the 8 th day.

\section{EXPERIMENTS AND RESULTS}

The content of the mediums on which the organisms were grown was varied in order to determine what effect this would have on enzyme production. Gelatin itself was first tried and proteolytic

12 Cited by Marras (Centralbl. f. Bakteriol., 1, O., 1914, 74, p. 505).

${ }^{13}$ Centralbl. f. Bakteriol., 1, O., 1904, 35, p. 1.

14 Biochem. Ztschr., 1912, 38, p. 252.

15 Compt. rend. Soc. de biol., 1905, 59, pp. 120, 195 and 197.

16 Biochem. Ztschr., 1910, 29, p. 104.

17 Centralbl. f. Bakteriol., 1, O., 1914, 74, p. 374. 
enzymes were found to be produced by each of the organisms used. These enzymes, however, were not specific gelatinases because, although they liquefied gelatin rapidly, they also promptly digested the casein. This agrees with the findings of De Waele and Vandevelde ${ }^{6}$ and others, and is the basis for some of the conclusions as to the identity of gelatinases and caseases.

When the bacteria were grown on the casein solution, proteases were again obtained which attacked both gelatin and casein and, with the qualitative methods employed, no difference between the activity of these ferments and the ones obtained from the gelatin mediums was apparent. However, later experiments lead us to conclude that with more accurate methods for the quantitative estimation of proteolysis some differences will very probably be found. The filtrates from cultures on meat-extract and meat-infusion both likewise were found to contain ferments which would rapidly digest both gelatin and casein.

After obtaining apparently identical ferments from these several mediums, all of which contained numerous complex proteins, the other extreme was resorted to, that is, a medium was utilized which contained no organic nitrogen. It is one which Magoon ${ }^{18}$ recommends for the cultivation of tubercle bacilli and on which all of the common bacteria will usually grow well. It is made up as follows:

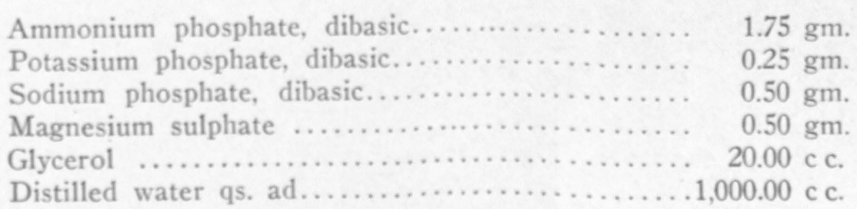

When all of the salts are dissolved, this is sterilized by fractional sterilization, after which it may be kept indefinitely and used as desired. Although this medium, due to the presence of the glycerin, is not strictly inorganic it will be called an "inorganic medium" in this paper for the sake of brevity.

When inoculated into this medium, which had been placed in small flasks, $100 \mathrm{cc}$ to a flask, the organisms all developed rapidly and within a few days a heavy growth was obtained. At the end of 8 days a portion from each flask was filtered and the sterile filtrate added to gelatin and to casein solution as described. But on incuba-

1s Washington Agricultural Experiment Station, Bull, 132. 
tion no digestion occurred in any of the tubes. Other portions of the cultures were filtered and tested at 14 and 21 days, but in no case were any enzymes obtained which would attack either the gelatin or the casein.

By means of the next experiments it was hoped to determine how close to gelatin and casein in chemical composition the mediums would have to be to stimulate the production of gelatinases and caseases. With this object in view peptone was added to the above described medium in a quantity sufficient to make a $1 \%$ solution. On this medium the organisms all grew vigorously, and it was found that they produced enzymes which would digest both gelatin and casein.

This showed the necessity for utilizing some substances still more simple as sources of organic nitrogen and, as asparagin is frequently used in nonprotein mediums, it was next tried, enough of it being added to the original medium to make a $1 \%$ solution. On this the bacteria showed rapid development and in the filtrates from the cultures enzymes were found to be present which both liquefied the gelatin and digested the casein, and with apparently equal rapidity.

These results led us to study the literature on the chemical composition of gelatin and casein by Fischer, Abderhalden and others. According to Matthews, ${ }^{19}$ in addition to various percentages of most of the amino-acids, both of the above proteins contain aspartic acid, gelatin $0.56 \%$ and casein $1.4 \%$. Gelatin also contains $16.5 \%$ glycocoll and casein none, while casein contains $4.5 \%$ tyrosin and $1.5 \%$ tryptophan and gelatin contains neither. Of these amino-acids tryptophan was not available, but glycocoll and tyrosin were utilized for our experiments, $1 \%$ solutions of each being made up with the "inorganic medium" as a base. .

In the mediums containing glycocoll each of the 3 organisms were allowed to develop as in previous experiments but growth was found to be more slow. However, after several days a vigorous growth appeared in each of the flasks, and at the end of 8 days the cultures were filtered and portions of the filtrates tested for enzymes in the manner already described. Each one of these filtrates from the mediums containing glycocoll showed marked liquefaction of gelatin, but had no action on the casein. The rate of the liquefaction of the gelatin was also marked, being noticeably more rapid than that caused by the filtrates from any of the mediums previously used, even from

19 Physiological Chemistry, 1916. 
gelatin itself. But on the casein solution there was no action, even when allowed to remain in the incubator for several days. Other samples from these cultures were filtered and tested at various intervals up to 3 weeks, but the results obtained were always the same.

On the mediums containing the $1 \%$ of tyrosin growth was more rapid but the filtrates less active. In the tubes of gelatin, which were inoculated with filtrates from this medium, there was absolutely no evidence of liquefaction, either at $20 \mathrm{C}$. or at $37 \mathrm{C}$.; but in the casein solutions there was quite marked digestion by the filtrates from the cultures of each of the organisms. This digestion, altho not so rapid as that caused by trypsin, was apparently of about the same intensity as that obtained with the filtrates from broth, gelatin, peptone and asparagin.

In tabular form these results appear as follows:

TABLE 1

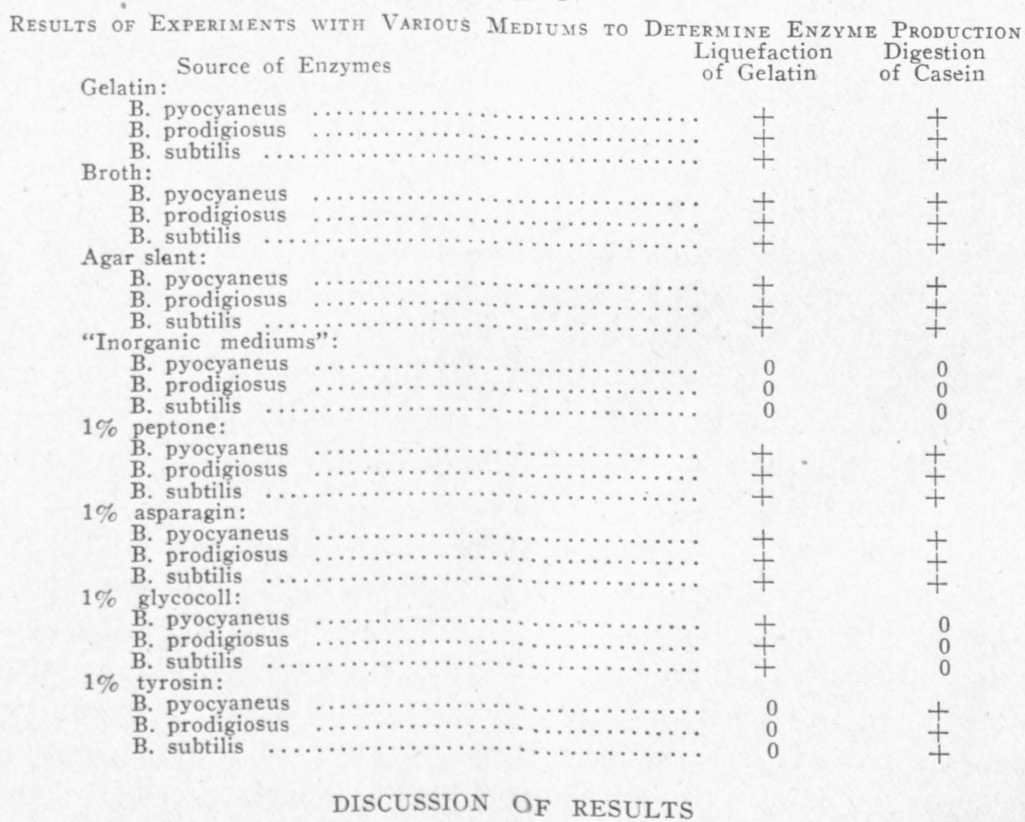

The fact that nonspecific proteases can be obtained from cultures on gelatin, casein and nutrient broth has frequently been mentioned and is of no special significance in this paper, except to show the basis for most of the conclusions as to the identity of proteolytic enzymes. 
These conclusions seem perfectly logical in view of such results, and the ones reached by us would have been very similar, had not experiments with other mediums thrown further light on the subject.

The finding of no gelatinases or caseases on mediums containing no organic nitrogen at first appears contradictory to the findings of some other writers, notably Jordan, ${ }^{20}$ Aubel and Colin, ${ }^{21}$ and Abbott and Gildersleeve. ${ }^{22}$ But, on close investigation of their work, one finds that the "nonprotein" mediums of which they write always contain organic nitrogen in one form or another. Jordan, for example, in his experiments varies the salt content of the mediums, but in each case asparagin is found to be present. Aubel and Colin use asparagin or ammonium aspartate as the source of nitrogen. With such findings we can well agree, but on mediums containing no organic nitrogen we are forced to conclude that enzymes are not liberated by the bacteria. These results seem significant in the study of enzyme formation and furnish further evidence that bacterial enzymes are not preformed in the cell but are manufactured by the organism as the need for them arises.

The formation of both gelatinases and caseases on the mediums containing $1 \%$ of peptone is not surprising and has very little significance because peptone is a substance of rather indefinite chemical composition, which is found as an intermediate step in the breaking down of all proteins. For this reason, if it stimulated the production of any proteases at all, these would be expected to attack one protein as well as any other.

With asparagin as a source of nitrogen the production of gelatinases and caseases at first seems surprising and appears as another argument against the specificity of proteases. It is one which has been mentioned in the literature and would be a strong one were it not for the fact that asparagin is an amin of asparatic acid which is present in both gelatin and casein. Thus, proteolytic enzymes formed on mediums containing asparagin as a source of nitrogen might be expected to attack casein as well as gelatin. In regard to enzyme production in mediums containing inorganic salts plus asparagin, Jordan ${ }^{20}$ states that the enzymes are produced in just as large amounts as they are in gelatin or in broth, but that a longer time is necessary. Our results, although not quantitative, seem to agree with this.

\footnotetext{
20 Biol. studies of pupils of W. T. Sedgwick, Boston, 1906, p. 124.

${ }_{21}$ Compt. rend Soc. de biol., 1913, 74, p. 790.

${ }_{22}$ Jour. Med. Research, 1903, 10, p. 42.
} 
As to the nature of this enzyme our work merely shows that it is proteolytic, digesting both gelatin and casein. Effront and Ehrlich, ${ }^{23}$ however, inoculated solutions of asparagin with yeast and obtained ammoniacal nitrogen. The filtrates of such cultures also had the property of breaking down asparagin and the amount transformed was proportionate to the time. This signified to them that amidase is formed which is responsible for the action. On the other hand, Walker and Kendall, ${ }^{24}$ after studying the proteolytic enzymes of B. proteus, conclude that the one which liquefies gelatin is in a sense at least a preparatory one, preparing the protein for assimilation and that "deaminization is an independent phenomenon, associated with the intracellular utilization of the products of proteolysis." This work makes it appear as though there must be two enzymes formed on asparagin, but it is the proteolytic enzyme rather than the deaminizing one with which we are interested.

On glycocoll we found growth to be less vigorous than on the other mediums. This agrees with the observations of Bielecki ${ }^{25}$ who found that bacteria will grow better on asparagin than on any of the other amino-acids which he investigated, but that some development is obtained on all. Franzen and Egger ${ }^{26}$ also found that of asparagin, alanin, and glycocoll, asparagin forms the best source of nitrogen for B. prodigiosus, while the least growth is obtained on glycocoll. The enzymes obtained from this medium were very marked in their action, the gelatin being liquefied with surprising rapidity and the casein remaining unchanged.

On the mediums containing tyrosin the results were just as striking, the gelatin showing absolutely no liquefaction while the casein was progressively digested. The results seem quite significant in view of the fact that gelatin contains glycocoll but no tyrosin, while casein contains tyrosin but no glycocoll.

The ultilization in a similar manner of other amino-acids, particularly tryptophan, would doubtless further demonstrate this point but, due to the shortage of chemicals in consequence of the present war, it has been impossible to obtain them for this piece of work. However, the ones which were used point very strongly toward the conclusion that the amino-acids play a very important part in the determination of specificity among proteolytic enzymes.

\footnotetext{
23 Compt. rend. Acad. de sc., 1907, 146, p. 779.

24 Jour. Infect. Dis., 1915, 17, p. 442.

${ }_{25}$ Compt. rend Soc. de biol., 1911, 70, p. 100.

26 Centralbl. f. Bakteriol., 1, Ref., 1915,63 , p. 49.
} 
It is as yet hard to say just how comprehensive the conclusions should be which follow from such findings; but it appears that, on mediums containing no organic nitrogen, no proteolytic enzymes are formed, and that, on mediums containing but one amino-acid as a source of nitrogen, the enzymes which are formed will attack only proteins which contain that particular amino-acid. In other words, this enzyme seems specific for proteins containing that one aminoacid. Thus, the enzymes formed on most amino-acids tend to show very little specificity because the great majority of amino-acids, like aspartic acid, are present in practically all of the proteins. Also, the ferments, which are formed on mediums containing either many aminoacids or a few more complex nitrogenous compounds, would have the ability to attack large numbers of proteins, thus appearing to be entirely without specificity.

Experiments similar to the ones described in the foregoing are apparently unmentioned in the literature. Consequently the results may offer a new foundation on which to base our ideas as to the specificity of bacterial proteolytic enzymes. That these enzymes are not specific for individual proteins has been the opinion of many reliable workers and yet the conclusion that one and the same enzyme breaks down all proteins does not follow from their work. They also state a priori that it is unreasonable to assume for each protein and protein derivative a special enzyme. The results of our experiments do not contradict this. They indicate rather that the number of ferments which a bacterial cell can liberate is limited and depends on the amino-acids present.

As to whether the amino-acids in the free and in the combined state exert the same influence on enzyme production has not yet been established. The results obtained by growing the bacteria on the usual protein mediums do not lead to definite conclusions concerning this point because one cannot be certain that these proteins do not contain some free amino-acids, particularly after having been exposed to the high temperatures necessary for sterilization. Some experiments at this laboratory to determine this point are as yet unfinished, but it is hoped that they may eventually throw some light on the subject. The method employed is as follows: Sterile gelatin is subjected under sterile conditions to dialysis for a time sufficient to remove from it all crystalloid substances. Then sterile salt solution is added to give the desired salt concentration and it is inoculated with bacteria which have 
first been transplanted several times on the mediums containing no organic nitrogen. The object of these transplants is to obviate the possibility of carrying any amino-acids or ferments onto the gelatin along with the bacteria. As can easily be seen, the difficulties in carrying out this technic are great and as yet no satisfactory results have been obtained. However, by a technic such as this we hope to procure some further definite information as to whether pure proteins stimulate the production of enzymes. This would confirm the work of Sperry and Rettger, ${ }^{27}$ who found that pure egg albumin, serum albumin, and edestin were unattacked by a variety of proteolytic bacteria in the absence of other organic sources of nitrogen.

But, whatever the results of this experiment may prove to be, the conclusions from those already completed will be unaffected, namely, that the amino-acids are important factors in the determination of the nature of the enzymes which are formed, and that these enzymes are probably not specific for the proteins but rather for the amino-acids which go to make them up.

In regard to the enzymes formed on complex proteins several possibilities suggest themselves: (1) that only one enzyme is formed, and that this is modified by the presence of the various amino-acids so as to attack them all, or (2) that a separate enzyme is formed to correspond to each amino-acid present, and that these different enzymes are present approximately in the same proportion as the amino-acids which stimulated their formation. From our work the latter possibility seems the more probable, although none of the results show this conclusively.

With such results as a basis, we may be able to modify somewhat our ideas of the formation and the action of bacterial proteolytic enzymes. First of all, the enzymes are dependent on some inherent property of the organisms themselves. This is evident from the fact that some bacteria do not have the ability to form certain ferments, no matter on what mediums or under what conditions they are cultivated. For example, B. typhosus and B. dysenteriae, etc., have never been known to form gelatinolytic nor caseinolytic enzymes, and, although B. coli produces an enzyme which will form indol from peptone, it liberates none which will attack gelatin.

A second factor, or group of factors, which influences enzyme formation may be called general conditions. This includes the temperature, the reaction of the medium, the time of growth, etc., all of

27 Jour. Biol. Chem., 1915, 20, p. 445. 
which have a greater or less effect on the production of enzymes by bacteria, and on which much exhaustive work has been done by such men as Kendall, Von Gröer, Jordan, Abbott and Gildersleeve, Bertiau, Emmerick, Fermi, etc. Their work shows that in the formation of enzymes there is for each organism a maximum, minimum and optimum temperature, and that in most cases the optimum is about $37 \mathrm{C}$. The optimum chemical reaction is also variable, a very slightly alkaline medium seeming best for the production of most enzymes. However, as they will act nearly as well in a neutral or slightly acid medium, this point seems to be of no great importance. The quantity of enzymes present in cultures of different ages has been discussed earlier in this paper. All of these observations, although of importance in the study of enzymes, show differences of quality only and so are not particularly pertinent to this question, for which reason they will not be discussed in greater detail.

A third and most important factor in determining the character of the enzymes produced is the composition of the medium on which they are formed. This is demonstrated by the experiments reviewed in this paper, the results of which may be put in general terms as follows: If a protein medium is inoculated with an organism which has the ability to form ferments to correspond to a large number of aminoacids, enzymes which will attack practically any protein can be obtained from the culture. This may be due to the fact that, apparently at least, ferments are formed to correspond to all of the amino-acids present, and that these ferments then attack the acids in whatever form they find them. On mediums containing less complex nitrogenous substances or only amino-acids the same bacteria will give off ferments to correspond only to the amino-acids present, and these ferments will attack only substances containing these same acids. The vigor with which they will attack these substances seems to depend on the relative amino-acid content of the mediums on which they are formed and that on which they act, namely, if the medium on which the enzymes are formed contains only asparagin and glycocoll and the medium on which they are inoculated contains only a small percentage of one or the other, the digestive action will be much less marked than it would be if the protein medium contained more of one or both of the same acids. That is, the amino-acid content of the medium determines the specificity of the enzymes formed: 
On the basis of these findings it seems that many of the so-called "irregularities of bacterial action" may be explained. Every bacteriologist finds organisms which, although corresponding according to morphology and pathogenicity to known types, show some "irregularity" in their action on culture mediums. Later, on a different lot of mediums or possibly at a different laboratory, the same organism may show the action on culture mediums which was previously expected, and the worker, at a loss for an explanation, concludes that it is merely another example of the "irregularity of bacterial action." Occasionally there may be some truth to this conclusion, but probably very often this "irregularity" would never have appeared if the chemical composition of mediums were always the same.

These same observations of the effect of mediums on bacterial ferments will probably furnish an explanation for many of the "new strains" of bacteria which are described, but are never verified by other workers. They usually differ from well established strains only in some minor points, and slight differences in the chemical composition of the mediums on which they are grown could well account for these.

Another phenomenon for which this conception of ferment activity seems to offer an explanation is the apparent incongruity of the action of some bacteria on mediums. For example, B. proteus and B. subtilis are well known to be strongly proteolytic and exhibit typical proteolytic actions, such as the liquefaction of gelatin and the formation of indol. On the other hand, B. coli and some of the dysentery group, although without action on gelatin, still form indol in large amounts from peptone. These organisms are not considered proteolytic and yet they unquestionably exhibit proteolytic activity when they split off tryptophan from peptone and then break down the tryptophan itself to form indol. If we accept the theory that all proteolytic enzymes are the same, we must expect these organisms which show proteolysis on peptone to liquefy gelatin. On the other hand, if we consider this in view of the findings given in this paper, the action does not appear at all surprising. Here are several organisms which have the inherent ability to form enzymes which will attack only one aminoacid and that is tryptophan. And in peptone we have a protein derivative which contains tryptophan, while gelatin is a protein in which no tryptophan is present. The explanation is self evident on this basis. 


\section{CONCLUSIONS}

On a medium containing no organic nitrogen, no proteolytic enzymes are formed by bacteria.

On gelatin, casein, broth, agar, and peptone enzymes are formed which will digest both gelatin and casein.

The ferments obtained from mediums containing amino-acids as the only source of organic nitrogen show various actions. The ones from asparagin digest both gelatin and casein; on glycocoll, no caseases are liberated; and on tyrosin, no gelatinases.

Proteolytic enzymes are apparently formed to correspond to the different amino-acids present in the medium and will then attack these acids whether combined or free.

These enzymes are not preformed in the bacterial cell but are dependent on the content of the medium on which it grows.

The specificity of proteolytic enzymes is resident in the amino-acids composing the proteins and not in the proteins themselves.

Differences in the chemical constituents of mediums may account for many of the unverified "new strains" of bacteria, the differentiation of which is based on some minor phase of their action on culture mediums. 